\title{
Oral Rehabilitation of Patients with Angle Class III Malocclusion and Teeth Loss through a Multidisciplinary Approach, Including Orthognathic Surgery and Implant Prosthetic Rehabilitation
}

\author{
Hakobyan Gagik ${ }^{1}$, Khachatryan Levon ${ }^{2}$, Khachatryan Grigor ${ }^{3}$, Tunyan Gegham ${ }^{4}$
}

\begin{abstract}
Aim: The aim of the study is to assess treatment success of teeth loss patients with class III skeletal malocclusion through a multidisciplinary approach, including orthognathic surgery and implant prosthetic rehabilitation.

Materials and methods: The present retrospective study investigated the 5-year clinical treatments outcomes 16 patients with class III malocclusion and teeth loss. Clinical, laboratory, radiological methods were used in the examination of patients. Surgical stage included sagittal bilateral osteotomy of the lower jaw and reposition it back (Le Fort I osteotomy). 7-8 months after the orthognathic surgery 132 implants were inserted. After 2 to 4 months of submerged healing period patients had received implant-fi ed prostheses.

Results: No serious intraoperative or immediate postoperative complications were noted. At the control examination after 6 months after surgery, from an X-ray examination we did not observe any clinical or radiological signs of inflamm tion in the area of osteotomy sites and titanium mini-plates. Success rate of implants after 5 years was $96.2 \%$.

Conclusion: After orthognathic surgery and dental implant prosthetic rehabilitation, the masticatory function, esthetics of the facial profil , and occlusion were improved. Patients expressed satisfaction with the result of treatment and improved quality of life.

Keywords: Implant prosthetic rehabilitation, Orthognathic surgery, Skeletal class III malocclusion.

International Journal of Prosthodontics and Restorative Dentistry (2020): 10.5005/jp-journals-10019-1262
\end{abstract}

\section{INTRODUCTION}

Malocclusion is one of the most common pathologies in the maxillofacial area, and the treatment of patients with this pathology remains an urgent problem. Treatment of skeletal class III malocclusion in an adult requires surgical procedures, with the aim to achieve normal occlusion and improve facial esthetics. Orthognathic surgery is a first approach to treat class III malocclusion and can be addressed with various surgical approaches. ${ }^{1,2}$ The type of surgical treatment depends upon the etiology of the malocclusion and may include sagittal split osteotomies, segmental osteotomies, Le-Forte I osteotomies, or some combination of the aforementioned. ${ }^{3,4}$

Orthognathic surgical procedures have been traditionally used in the dentate patient to correct a skeletal malocclusion. However, orthognathic surgery is often recommended for the adult patient presenting with a skeletal malocclusion and teeth loss a desire to restore esthetic and functional relationship. ${ }^{5}$ Tooth loss can have an effect on a patient's quality of life (QoL) due to poor masticatory function, speech, and dissatisfaction with appearance. Oral rehabilitations of patients with skeletal malocclusion and teeth loss are challenging procedures and are challenged by the skeletal discrepancies of the maxilla and the mandible. ${ }^{6}$

Conventional restorations as removable prostheses can be a limitation for patients with skeletal malocclusions due to poor occlusions. For complete denture wearers, the chew's ability is significantly less efficient, and this may have consequences on QoL of those patients.

\footnotetext{
${ }^{1-4}$ Department of Oral and Maxillofacial Surgery, Yerevan State Medical University, Yerevan, Armenia

Corresponding Author: Hakobyan Gagik, Department of Oral and Maxillofacial Surgery, Yerevan State Medical University, Yerevan, Armenia, Phone: +374091403038, e-mail: prom_hg@yahoo.com

How to cite this article: Hakobyan G, Levon K, Grigor K, et al. Oral Rehabilitation of Patients with Angle Class III Malocclusion and Teeth Loss through a Multidisciplinary Approach, Including Orthognathic Surgery and Implant Prosthetic Rehabilitation. Int J Prosthodont Restor Dent 2020;10(1):12-20.

Source of support: Nil

Confli t of interest: None
}

Over the past decade, dental implant prosthetic rehabilitation is used for replacing missing teeth in various clinical situations. Patients treated with dental implants to support prostheses have better masticatory function, higher satisfaction, and QoL than patients treated with conventional complete dentures. ${ }^{7-9}$ Without the use of implants to create stability and retention, placing denture teeth can create instability of the prosthesis. ${ }^{10}$

Patients with dentofacial deformities orthognathic surgery and implant prosthetic treatment may be possible to complex oral rehabilitation and are providing effects on the speech, chewing, smile and patient respiratory parameters. ${ }^{11}$

The most commonly encountered complications in orthognathic surgery are postoperative infection, hemorrhage, neurosensory

() The Author(s). 2020 Open Access This article is distributed under the terms of the Creative Commons Attribution 4.0 International License (https://creativecommons. org/licenses/by-nc/4.0/), which permits unrestricted use, distribution, and non-commercial reproduction in any medium, provided you give appropriate credit to the original author(s) and the source, provide a link to the Creative Commons license, and indicate if changes were made. The Creative Commons Public Domain Dedication waiver (http://creativecommons.org/publicdomain/zero/1.0/) applies to the data made available in this article, unless otherwise stated. 
disturbances, and incorrect condylar position. ${ }^{6,12,13}$ Prevention of complications depends largely on the knowledge and skills of the surgeon; a multidisciplinary approach would prevent and minimize intra- and post-op complications.

Rehabilitation of patients with class III malocclusion and teeth loss is one of the urgent problems of orthognathic surgery. In this group of patients to ensure accurate diagnosis, optimal planning, and appropriate treatment, a comprehensive interdisciplinary approach is often necessary, in which orthopedists, orthodontists, periodontists, prosthodontist and oral and maxillofacial surgeons should participate. ${ }^{14-16}$ The interaction established among diffe ent specialties provides patients with a comprehensive treatment plan. ${ }^{17-19}$

The objective of the study is to assess treatment success of teeth loss patients with class III skeletal malocclusion through a multidisciplinary approach, including orthognathic surgery and implant prosthetic rehabilitation.

\section{Materials and Methods}

16 patients with class III skeletal malocclusion and teeth loss (5 patients complete and 11 patients partial edentulous) were treated for orthognathic surgery and implant prosthetic rehabilitation between 2014 and 2019. The ages of the patients ranged between $26-43$ years ( 7 males and 9 females). All patients presented functional and esthetic complaints.

Clinical, laboratory, and radiological methods were used in the examination of patients. Patients were evaluated by preoperative and postoperative outcomes using computed tomography (CT) scan evaluation. Clinical data included demographic and clinical variables: (1) gender, (2) age, (3) method of orthognathic surgery, and (4) type of implant surgery and dental prosthetic rehabilitation.

Anatomical and topographic assessment of the relationships of the upper and lower jaw, evaluation of occlusal relationships and evaluation of dental status was done with the help of pre-treatment facial photographs (Figs $1 \mathrm{~A}$ to $\mathrm{C}$ ) and $\mathrm{CT}$ images (Figs $2 \mathrm{~A}$ and $\mathrm{B}$ ).

The treatment plan included detailed analysis of occlusion, space for restoration (Figs $3 A$ to $C$ ), bone quantity and density, determination of which teeth were essential for prosthodontic treatment, and which teeth had a hopeless periodontal prognosis (Figs 3D and E). Oral hygiene was assessed. Final treatment plan was drawn up using a team approach with orthodontics, periodontics, oral and maxillofacial surgeons, and prosthodontics. The orthognathic surgery was planned with the aid of three-dimensional (3D) CT. Data obtained from CT scan procedure can view the virtual 3D model from different angles using the software to customize the treatment plan. The purpose of treatment was the elimination of abnormal development of the jaws, interlocking dentition, and dental defects. The choice of surgical treatment is determined by the type of anomaly and the degree of deformation.

The complex oral rehabilitation was performed with orthognathic surgery followed by implant prosthetic treatment. All patients were fully informed of the protocol of the present study and signed a detailed informed consent.

\section{Surgical Technique}

The surgical procedure included two stages: orthognathic surgery and implant installation surgery performed 7-8 months after reconstruction. All surgical procedures (orthognathic surgery and implant installation) were performed by one surgical team.

Le Fort I osteotomy and mandibular orthognathic surgery were performed under general anesthesia. After Le Fort I osteotomy, the maxillary alveolar process was anteriorly positioned as planned by CT analysis and was stabilized using titanium miniplates and screw. After sagittal split osteotomy, the mandible was repositioned posteriorly and was stabilized in the desired position using titanium mini-plates and screw or wire fix tion (Figs 4A to D). Preoperative antibacterial therapy was given a day prior to surgery and was continued for another 5 days postoperatively to prevent inflamm tory complications.

Intraoperative and postoperative complications such as bleeding, swelling, pain and nasal bleeding, neurosensory disorders, and infection were recorded. We evaluated the residual effects of neurosensory disorders in three patient which disappeared within 3-6 weeks.

After orthognathic surgery, the esthetics of the facial profil and occlusion was improved significa tly. After 7-8 months of the orthognathic surgery, 132 implants were inserted (Figs 5A and B). After implant insertion, the cover screw was connected. The mucoperiosteal flap was carefully sutured to submerge the implants. Implant length and diameter were chosen based on the bone volume in the implant sites and based on the prosthetic indication. The diameter of the implants used was $3.75-4.5 \mathrm{~mm}$ and length was $10-15 \mathrm{~mm}$. Postoperative clinical and radiographic controls were made regularly; the criteria for implant success were assessed. The dental prosthetic phases started 3-5 months after implant submerged healing period. The cover screws were removed and changed into healing abutments and prosthetic fabrication was carried out. Patients had received implant-

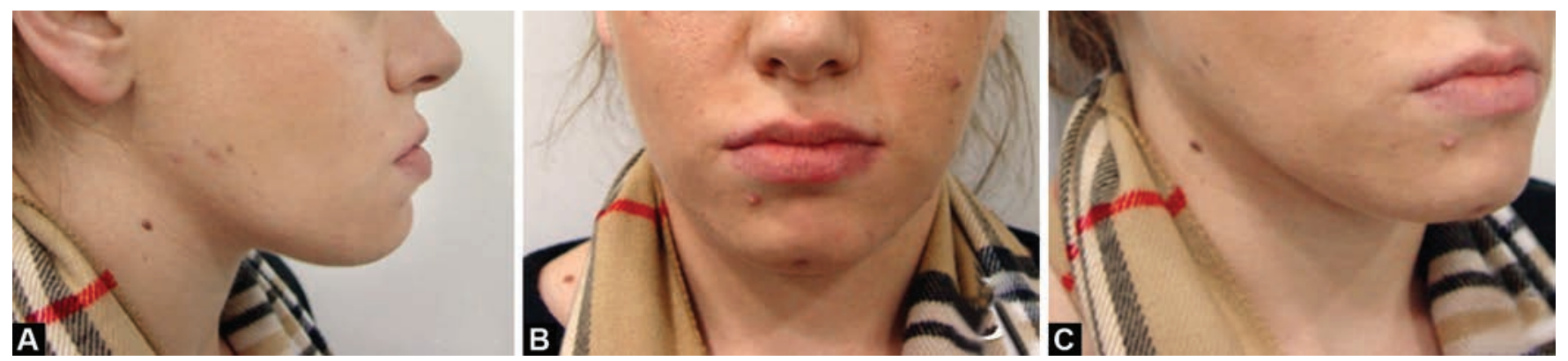

Figs 1 A to C: Pretreatment facial photographs: (A) Lateral view; (B) Frontal view; (C) Oblique view 

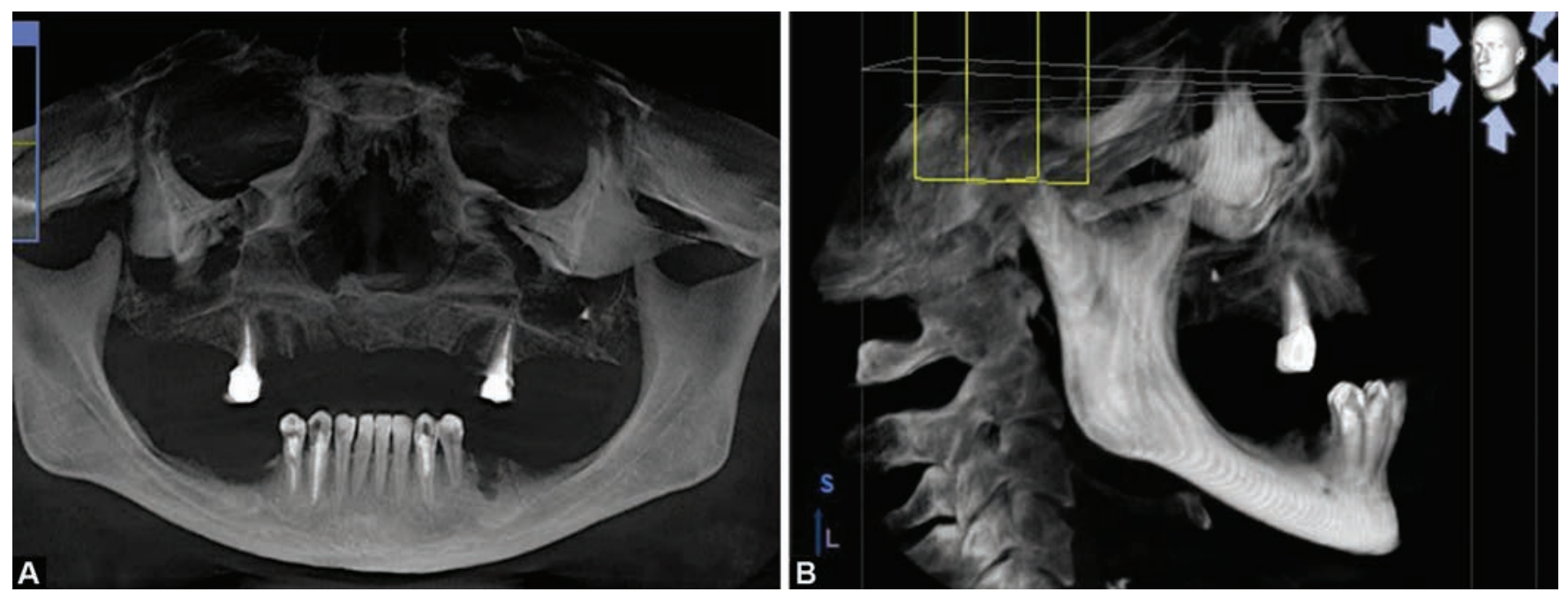

Figs 2A and B: (A) Cephalometric view; (B) Panoramic view of CT before orthognathic surgery
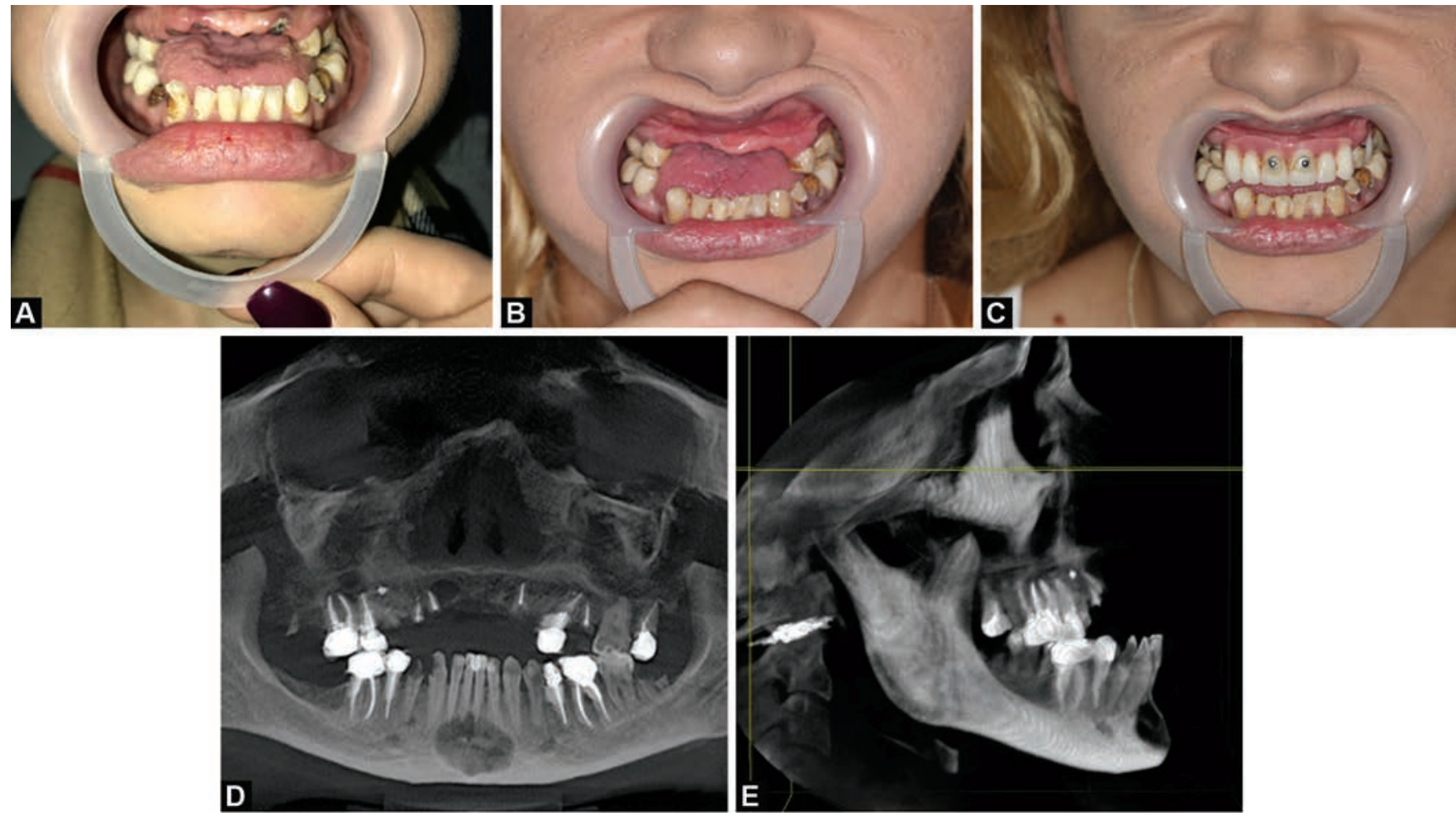

Figs 3A to E: Intraoral frontal view. (A) Intraoral examination identified an angle class III malocclusion with narrow and retrognathic maxilla; (B) In front part of maxilla, alveolar bone loss after extraction of hopeless teeth; (C) Partial denture upper jaw; (D) Cephalometric view; (E) Panoramic view of CT before orthognathic surgery

bridge and hybrid denture that provided ideal facial balance and occlusion (Figs $6 \mathrm{~A}$ to $\mathrm{E}$ ). The prosthetic indication was made according to each patient clinical condition in order to achieve the highest function and esthetic.

An implant was considered to have failed (clinical or absolute failure) if it had any of the following conditions: pain on function, mobility, radiographic bone loss $>1 / 2$ the length of the implant, uncontrolled exudate, or was no longer in the mouth. ${ }^{20}$
Clinical examination was performed to evaluate peri-implant and periodontal tissue and implant stability. Successes of oral implant rehabilitation were prosthesis success, implant success, complications, probing pocket depths, marginal bleeding, and bone marginal bone loss (MBL).

Radiograph was used to detect any bony abnormality and evaluate alveolar bone around each implant and made as average value. Postsurgical change in marginal bone level was assessed by 

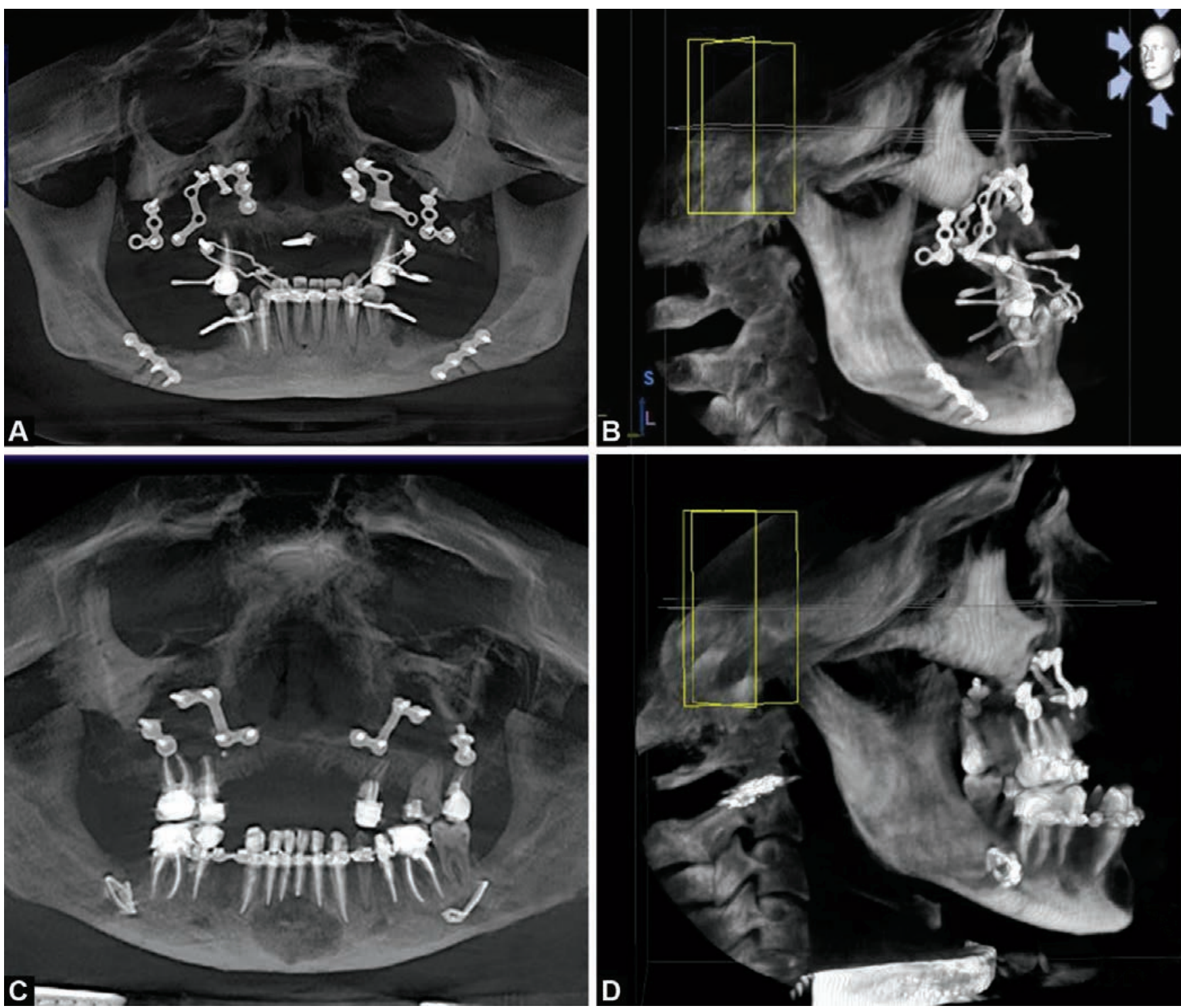

Figs 4A to D: CT images after orthognathic surgery: (A) Cephalometric view; (B) Panoramic view; (C) Cephalometric view; (D) Panoramic view

digital X-ray that was taken immediately (baseline for comparison) and 3 months after implant installation, after prosthesis loading, 1 year, 3 years, and 5 years after implant installation.

\section{Statistical Analysis}

Statistics were used to calculate and analyze the mean MBL of implants. The differences between follow-up periods were tested by paired Student's $t$ test. All analyses were carried out using SPSS (SPSS Software Company, Chicago, IL, USA). The $p$ values $<0.05$ were considered statistically significant.

\section{RESULTS}

During the clinical examination, the state of the temporomandibular joint (TMJ) and the state of the prostheses on the implants were evaluated. The treatment objective was to achieve adequate esthetics profile and to construct biomechanically favorable prosthesis to provide efficient masticatory function. During a clinical examination, we evaluated the general condition of the patient and revealed the presence of complaints of pain in the region of the upper and lower jaws, TMJ, and the presence of inflamm tory phenomena in the area of dental implants and titanium mini-plates.

No serious intraoperative or immediate postoperative complications were noted. Two patients had a minor neurosensory complication which disappeared within 3-4 weeks. This complication did not impede rehabilitation with dental implants.

A total of 132 implants were installed in 16 patients. At the control examination 3 months after implant installation, after prosthesis loading, 1 year, 3 years, and 5 years after implant installation, an X-ray examination was performed to determine the status of the osteotomy area, the status of dental implants, and the mean MBL of implants were presented in Table 1. 

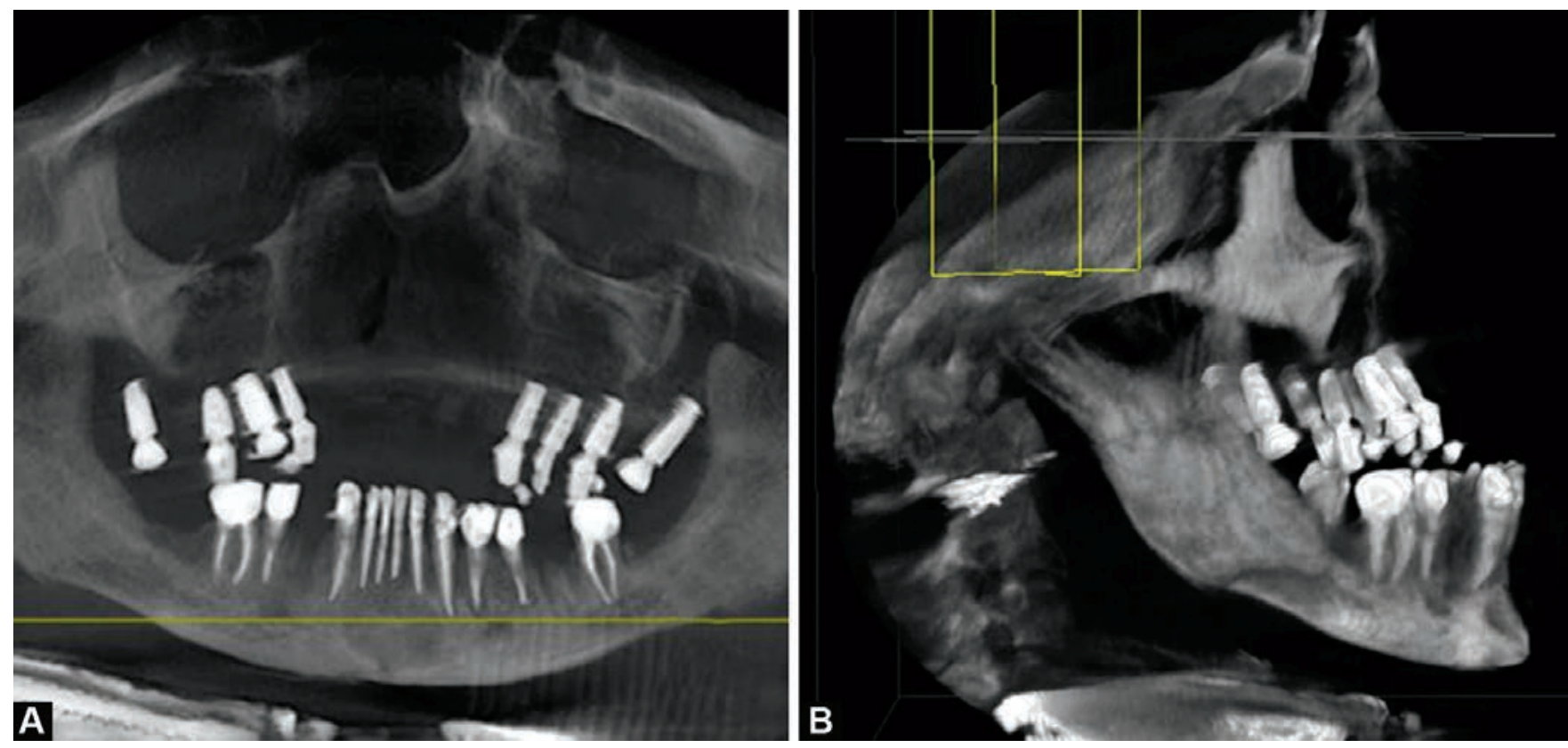

Figs 5A and B: (A) Cephalometric view; (B) Panoramic view of CT after dental implant placement
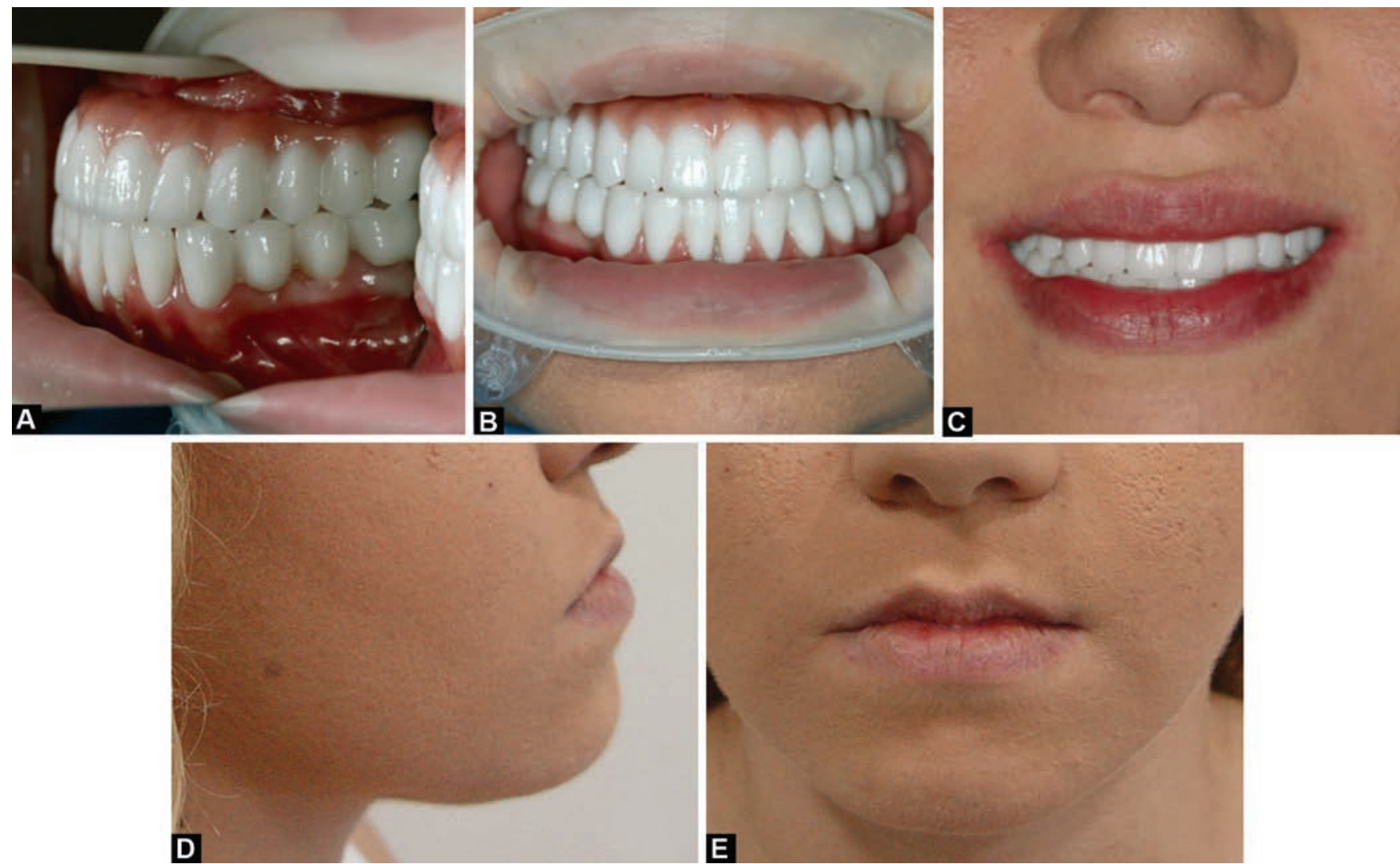

Figs $6 \mathrm{~A}$ to $\mathrm{E}:(\mathrm{A}-\mathrm{C})$ Intraoral pictures of the patient after prosthodontic treatment showing occlusion; (D-E) Photographs after implant prosthetic rehabilitation showing improved facial balance of the patient 
Oral Rehabilitation of Patients with Angle Class III Malocclusion and Teeth Loss Th ough a Multidisciplinary Approach

Table 1: A table with the individual patients

\begin{tabular}{|c|c|c|c|c|c|c|}
\hline Patients & Age & Gender & Method of surgery & Implantation site & Number of implants & Prosthesis \\
\hline N. 1 & 26 & $M$ & $\begin{array}{l}\text { Le Fort I osteotomy and mandibular } \\
\text { orthognathic surgery }\end{array}$ & Mandible & 5 & Bridge \\
\hline N.2 & 43 & M & $\begin{array}{l}\text { Le Fort I osteotomy and mandibular } \\
\text { orthognathic surgery }\end{array}$ & Maxilla, mandible & 12 & Hybrid denture \\
\hline N.3 & 34 & $\mathrm{~F}$ & $\begin{array}{l}\text { Le Fort I osteotomy and mandibular } \\
\text { orthognathic surgery }\end{array}$ & Maxilla & 8 & Bridge \\
\hline N.4 & 42 & M & $\begin{array}{l}\text { Le Fort I osteotomy and mandibular } \\
\text { orthognathic surgery }\end{array}$ & Maxilla, mandible & 10 & $\begin{array}{l}\text { Bridge } \\
\text { Hybrid denture }\end{array}$ \\
\hline N.5 & 28 & $\mathrm{~F}$ & $\begin{array}{l}\text { Le Fort I osteotomy and mandibular } \\
\text { orthognathic surgery }\end{array}$ & Mandible & 6 & Bridge \\
\hline N.6 & 35 & $\mathrm{~F}$ & $\begin{array}{l}\text { Le Fort I osteotomy and mandibular } \\
\text { orthognathic surgery }\end{array}$ & Maxilla, mandible & 12 & $\begin{array}{l}\text { Hybrid denture } \\
\text { Bridge }\end{array}$ \\
\hline N.7 & 31 & M & $\begin{array}{l}\text { Le Fort I osteotomy and mandibular } \\
\text { orthognathic surgery }\end{array}$ & Maxilla, mandible & 14 & Bridge \\
\hline N.8 & 29 & $\mathrm{~F}$ & $\begin{array}{l}\text { Le Fort I osteotomy and mandibular } \\
\text { orthognathic surgery }\end{array}$ & Maxilla, mandible & 10 & Bridge \\
\hline N.9 & 37 & M & $\begin{array}{l}\text { Le Fort I osteotomy maxillary alveolar } \\
\text { process }\end{array}$ & Maxilla, mandible & 8 & $\begin{array}{l}\text { Hybrid denture } \\
\text { Bridge }\end{array}$ \\
\hline N.10 & 32 & $\mathrm{~F}$ & $\begin{array}{l}\text { Le Fort I osteotomy and mandibular } \\
\text { orthognathic surgery }\end{array}$ & Maxilla, mandible & 10 & $\begin{array}{l}\text { Hybrid denture } \\
\text { Bridge }\end{array}$ \\
\hline N.11 & 28 & $M$ & $\begin{array}{l}\text { Le Fort I osteotomy and mandibular } \\
\text { orthognathic surgery }\end{array}$ & Mandible & 6 & Bridge \\
\hline N.12 & 32 & $\mathrm{~F}$ & $\begin{array}{l}\text { Le Fort I osteotomy maxillary alveolar } \\
\text { process }\end{array}$ & Maxilla, mandible & 14 & Bridge \\
\hline N.13 & 27 & $\mathrm{~F}$ & $\begin{array}{l}\text { Le Fort I osteotomy and mandibular } \\
\text { orthognathic surgery }\end{array}$ & Maxilla & 8 & Bridge \\
\hline N.14 & 34 & $\mathrm{~F}$ & $\begin{array}{l}\text { Le Fort I osteotomy maxillary alveolar } \\
\text { process }\end{array}$ & Maxilla, mandible & 14 & Bridge \\
\hline N.15 & 38 & M & $\begin{array}{l}\text { Le Fort I osteotomy and mandibular } \\
\text { orthognathic surgery }\end{array}$ & Maxilla & 10 & Bridge \\
\hline N.16 & 33 & $\mathrm{~F}$ & $\begin{array}{l}\text { Le Fort I osteotomy and mandibular } \\
\text { orthognathic surgery }\end{array}$ & Mandible & 5 & Bridge \\
\hline
\end{tabular}

We did not observe any clinical or radiological signs of inflammation in the area of osteotomy sites and titanium miniplates. The implants were osseointegrated; radiographies revealed no radiolucency around the implants and no sign of excessive peri-implant bone loss. Patients presented with healthy soft tissue.

A stable orthognathic occlusion was achieved in all patients, no recurrence of the disease was observed, which confirms the appropriateness of using dental implants for prosthetics in the complex treatment of patients with skeletal malocclusion and teeth loss.

Total, 132 implants were placed in 16 patients, 2 impants failed to osseointegrate and 3 implants failed after 3 years of loading due to peri-implantitis.

The success rates of implants in maxilla were $96.4 \%$, and the success rates of implants in mandible were $95.8 \%$. There were no statistically significant differences in the success rate among implantation sites, although the success rates in maxilla were higher than mandible (Table 2).
The success rates of patients with ages less than 30 years old were $97.1 \%$, and the success rates of patients with ages greater than 30 years old were about $95.9 \%$. There were no statistically significant differences in the success rate among ages of patients, although the success rates of patients with ages less than 30 years old were higher than those with age greater than 30 years old (Table 3 ).

Mean MBL at 3 months after implant installation, after prosthetic loading, 1 year, 3 years, and 5 years after installation was significantly higher than MBL at the time of implant installation $(p<0.05)$. Mean marginal bone loss (MBL) at prosthetic loading was significantly higher than at 3 months post-installation, and mean $\mathrm{MBL}$ at 1 year after installation was significantly greater than at prosthetic loading. MBL change after 3 and 5 years post-installation did not differ significantly ( $p<0.05$ ) (Table 4).

The mean MBL after the first year was $0.81 \pm 0.42 \mathrm{~mm}$, the mean cumulative MBL after 5 years was $1.42 \pm 0.53 \mathrm{~mm}$, and the MBL change each year was not greater than $0.2 \mathrm{~mm}$. These MBL results are within the threshold indicating success. ${ }^{21}$ 
Oral Rehabilitation of Patients with Angle Class III Malocclusion and Teeth Loss Th ough a Multidisciplinary Approach

Table 2: Success rate of implants among implantation site

\begin{tabular}{lll}
\hline Implantation site & Success/fail (total) & Survival rate (\%) \\
\hline Maxilla & $81 / 3(84)$ & 96.4 \\
Mandible & $46 / 2(48)$ & 95.8 \\
Total & $127 / 5(132)$ & 96.2 \\
\hline
\end{tabular}

Table 3: Success rate of implants among ages of patients

\begin{tabular}{|c|c|c|c|}
\hline Patients age & $\begin{array}{l}\text { Patients } \\
\text { number }\end{array}$ & $\begin{array}{l}\text { Success/fail } \\
\text { (total) }\end{array}$ & $\begin{array}{l}\text { Survival } \\
\text { rate (\%) }\end{array}$ \\
\hline $\begin{array}{l}\text { Patients with age less than } \\
30 \text { years }\end{array}$ & 5 & $34 / 1(35)$ & 97.1 \\
\hline $\begin{array}{l}\text { Patients with age greater than } \\
30 \text { years old }\end{array}$ & 11 & $93 / 4$ (97) & 95.9 \\
\hline
\end{tabular}

There were two groups regarding prosthetic indication, including bridge and hybrid denture. The difference between MBL value at 5 years post-installation and MBL at prosthetic loading of the bridge group was $0.94 \pm 0.31 \mathrm{~mm}$, of the hybrid denture group was $0.76 \pm 0.28 \mathrm{~mm}(p<0.05)$ (Table 5). Mean MBL bridge prosthesis group was significantly higher than hybrid denture prosthesis group $(p<0.05)$.

The results showed that implant treatment is effective to improve patients' masticatory efficiency. The gum initially had a greenish color and became more-and-more reddish with the duration and intensity of chewing, and there is a strong correlation between color change and masticatory performance and ability. Masticatory efficiency correlated with occlusal contacts, occlusal area of natural teeth, and the number of posterior teeth. Patients with $<20$ teeth have higher scores in self-administered oral health impact profi e (OHIP) questionnaires than those with more teeth.

The subjects completed OHIP before the surgery (T0) and 1 week after definitive prosthesis placement (T2). Improvement of oral health-related QoL (OHRQoL) was observed after the placement of a definitive prosthesis compared with that preoperatively. OHIP score significantly decreased at T2. Pre- and posttreatment OHIP sum scores were 47 and 13 , respectively $(p<001)$. Treatment with implant-based fixed prosthesis in patients with angle class III malocclusion and teeth loss results in an improved OHRQoL and satisfaction regarding dental appearance, ability to chew, and speech.

After orthognathic surgery and dental implant prosthetic rehabilitation, the esthetics of the facial profile and occlusion was improved. Patients expressed satisfaction with the result of treatment and improved QoL.

\section{Discussion}

Oral rehabilitation of patients with angle class III malocclusion and teeth loss due to difficulty sometimes requires surgical, orthodontic, and prosthetic treatment combination. The main objectives of this interdisciplinary approach are to restore the facial and dental harmony and functional occlusion. ${ }^{22-25}$ The best result of the operation is achieved only with a team approach.

Orthognathic surgery is distinguished by a high degree of predictability of the postoperative result and fully restored occlusion of the dentition. Harmony of the face and smile when performing a comprehensive orthognathic surgery of patients with
Table 4: The marginal bone loss (MBL) of dental implants at evaluated time points

\begin{tabular}{|c|c|c|c|}
\hline \multicolumn{2}{|l|}{ Time $(T)$ after implantation } & \multicolumn{2}{|c|}{$\begin{array}{l}\text { The mean marginal bone } \\
\text { loss }(\mathrm{MBL})^{*}\end{array}$} \\
\hline \multicolumn{2}{|l|}{ (T1) 3 months after implant installation } & \multicolumn{2}{|c|}{$0.31 \pm 0.22$} \\
\hline \multicolumn{2}{|l|}{ (T2) after prosthesis loading } & \multicolumn{2}{|c|}{$0.49 \pm 0.21$} \\
\hline \multicolumn{2}{|l|}{ (T3) 1 year after implant installation } & \multicolumn{2}{|c|}{$0.81 \pm 0.42$} \\
\hline \multicolumn{2}{|l|}{ (T4) 3 years after implant installation } & \multicolumn{2}{|c|}{$1.13 \pm 0.54$} \\
\hline \multicolumn{2}{|l|}{ (T5) 5 years after implant installation } & \multicolumn{2}{|c|}{$1.42 \pm 0.53$} \\
\hline \multicolumn{4}{|c|}{$\begin{array}{l}\text { *Mean MBL at } \mathrm{T} 1, \mathrm{~T} 2, \mathrm{~T} 3, \mathrm{~T} 4 \text { and } \mathrm{T} 5 \text { was higher than at implant installation } \\
(p<0.05)\end{array}$} \\
\hline \multicolumn{4}{|c|}{$\begin{array}{l}\text { Table 5: MBL of each prosthesis group at prosthetic loading and } 5 \text { year } \\
\text { after implant installation }\end{array}$} \\
\hline Time after implantation & \multicolumn{2}{|c|}{ Bridge } & Hybrid denture \\
\hline After prosthetic loading & \multicolumn{2}{|c|}{$0.51 \pm 0.28$} & $0.47 \pm 0.23$ \\
\hline 5 years after implant installation & \multicolumn{2}{|c|}{$1.45 \pm 0.61$} & $1.23 \pm 0.34$ \\
\hline $\begin{array}{l}\text { Difference between } M B L \text { value at } \\
5 \text { years post-installation and MBL at } \\
\text { prosthetic loading }\end{array}$ & \multicolumn{2}{|c|}{$0.94 \pm 0.31$} & $0.76 \pm 0.28$ \\
\hline
\end{tabular}

skeletal deformities of the maxillofacial area should be achieved by detailed planning of the orthodontic, surgical, and orthopedic stages. ${ }^{26}$

Orthognathic surgery can play an important role in complex restorative dental problems that cannot be successfully managed in the presence of a jaw size discrepancy. ${ }^{27-30}$ In cases with teeth loss, implant therapy is a necessary step to restore the masticatory function and should be included in the treatment plan in the early stages. Restoration of the dentition plays an important role in the treatment of this category of patients. Implant therapy allows to increase the functional and esthetic efficiency combination treatment for patients with class III malocclusion and edentulous jaws.

Alternatively, removable denture represents a second treatment option for these patients. However, in patients with class III malocclusion and teeth loss, it is difficult to achieve a satisfactory esthetic result with conventional prosthetic restoration, and its functionally and esthetically effectiveness is lower compared to implant-fixed prostheses. Implant-retained restorations present considerable advantages over removable partial dentures for missing teeth including a more stable occlusion and preservation of bone.

This study is based on an analysis of the results of treatment of 16 patients with skeletal form class III malocclusion and teeth loss who underwent combination of orthognathic surgery (maxillary Le Fort I osteotomy and mandibular setback) procedure and implant prosthetic rehabilitation. Planning and evaluation of the quality of treatment was carried out on the basis of a detailed assessment of the esthetic parameters of the face using clinical photography and $\mathrm{X}$-ray examination of the jaws in the front and side projections. The functional and esthetic rehabilitation was performed with orthognathic surgery, dental implants, and prosthodontic therapy to restore missing tooth and occlusion.

We considered successful treatment criteria: the normal position of the TMJ with both sides; achievement of central 
occlusion; the state of the chewing apparatus, allowing completely perform a chewing function; and patient satisfaction with their appearance.

The use of dental implants in the treatment of patients with skeletal form class III malocclusion and teeth loss allows to achieve a stable state of occlusion in the postoperative period. As a result of complex treatment, the patients were successfully rehabilitated and correction of the anteroposterior discrepancy between the dental arches with no recurrent malocclusion.

The long-term results of the use of dental implants in the complex treatment of such patients have been evaluated. Dental implantation is the best choice for complex oral rehabilitation of patients with class III malocclusion and teeth loss for cases similar to that demonstrated in the present report. Treatment not only restored function and esthetics but also showed a positive psychological impact and thereby improved perceived QoL.

The multidisciplinary approach proved to be effective in overcoming the challenges.

The teamwork of the team of doctors is the key to successful treatment of these patients and accordingly leads to patient satisfaction with the quality of the treatment carried out.

\section{Conclusion}

Dental implant prosthetic rehabilitation is the method of choice in the complex treatment of patients with skeletal form class III malocclusion and total or partial teeth loss. Dental implantation in such cases provides a complete occlusion efficient masticatory function and significantly reduces the risk of recurrence.

\section{References}

1. Fox GL, Tilson HB. Mandibular retrognathia: a review of the literature and selected cases. J Oral Surg 1976;34(1):53-61.

2. de Lir ALS, de Moura WL, Oliveira Ruellas AC, et al. Long-term skeletal and profile stability after surgical-orthodontic treatment of class II and class III malocclusion. J Craniomaxillofac Surg 2013;41(4):296. DOI: 10.1016/j.jcms.2012.10.001.

3. Sato FRL, Asprino L, Consani S, et al. A comparative evaluation of the hybrid technique for fixation of the sagittal split ramus osteotomy in mandibular advancement by mechanical, photoelastic, and finite element analysis. Oral Surg Oral Med Oral Pathol Oral Radiol 2012;114(5 Suppl):S60-S68. DOI: 10.1016/j.tripleo.2011.08.027.

4. Park JU, Baik SH. Classification of angle class III malocclusion and its treatment modalities. Int J Adult Orthod Orthognath Surg 2001;16(1):19-29.

5. Benech A, Mazzanti C, Arcuri F, et al. Simultaneous Le Fort I osteotomy and computer-guided implant placement. J Craniofac Surg 2011;22(3):1042-1046. DOI: 10.1097/SCS.0b013e318210765d.

6. Sakar O, Beyli M, Marsan G. Combined prosth-odontic and orthodontic treatment of a patient with a class III skeletal malocclusion: a clinical report. J Prosthet Dent 2004;92(3):224-228. DOI: 10.1016/j.prosdent.2004.06.002.

7. Moraschini V, Poubel LA, Ferreira VF, et al. Evaluation of survival and success rates of dental implants reported in longitudinal studies with a follow-up period of at least 10 years: a systematic review. Int J Oral Maxillofac Surg 2015;44(3):377-388. DOI: 10.1016/j.ijom.2014. 10.023.

8. Honda $\mathrm{K}$, Hirota M, Iwai T, et al. Orthognathic surgery and implantsupported bridge in a class III patient injured in a motor vehicle accident. J Craniofacial Surgery 2018;29(3):296-298. DOI: 10.1097/ SCS.0000000000004339.
9. Bakke $M$, Holm B, Jensen $B L$, et al. Unilateral,isometric bite force in eight 68-year old woman and men related to occlusal factors. Scand J Dent Res 1990;98(2):149-158. DOI: 10.1111/j.1600-0722.1990. tb00954.x.

10. Rendell J, Grasso JE, Gay T. Retention and stability of the maxillary denture function. J Prosthet Dent 1995;73(4):344-347. DOI: 10.1016/ s0022-3913(05)80329-4 Foltán R, Hoffmannová J, Pavlíková G. The influence of orthognathic surgery on ventilation during sleep. Int $J$ Oral Maxillofac Surgery 2011;40:146-149.

11. Kämmerer PW, Wolf JM, Dau M, et al. Orthognathic surgery for correction of skeletal class III malocclusion using osseointegrated dental implants: a clinical case letter. J Oral Implantol 2020;46(2): 146-152. DOI: 10.1563/aaid-joi-D-19-00113.

12. Westermark A, Bystedt $H$, von Konow L. Inferior alveolar nerve function after sagittal split osteotomy of the mandible: correlation with degree of intraoperative nerve encounter and other variables in 496 operations. British Journal of Oral and Maxillofacial Surgery 1998;36(6):429-433. DOI: 10.1016/S0266-4356(98)90458-2.

13. Acebal-Bianco F, Vuylsteke PL, Mommaerts MY, et al. Perioperative complications in corrective facial orthopedic surgery: a 5-year retrospective study. J Oral Maxillofac Surg 2000;58(7):754-760. DOI: 10.1053/joms.2000.7874.

14. Buttke TM, Profitt WR. Referring adult patients for orthodontic treatment. J Am DentAssoc 1999;130(1):73-79. DOI: 10.14219/jada. archive.1999.0031.

15. Williams AC, Shah H, Sandy JR, et al. Patients' motivations for treatment and their experiences of orthodontic preparation for orthognathic surgery. J Orthod 2005;32(3):191-202. DOI: 10.1179/146531205225021096.

16. Pinho $T$, Neves $M$, Alves $C$. Multidisciplinary management including periodontics, orthodontics, implants, and prosthetics for an adult. Am J Orthod Dentofacial Orthop 2012;142(2):235-245. DOI: 10.1016/ j.ajodo.2010.10.026.

17. Uribe F, Janakiraman N, Nanda R. Interdisciplinary approach for increasing the vertical dimension of occlusion in an adult patient with several missing teeth. Am J Orthod Dentofacial Orthop 2013;143(6):867-876. DOI: 10.1016/j.ajodo.2012.05.022.

18. Misch $C E$, Perel $M L$, Wang $H L$, et al. Implant success, survival, and failure: the international congress of oral implantologists (ICOI) Pisa consensus conference. Implant Dent 2008;17(1):5-15. DOI: 10.1097/ ID.0b013e3181676059.

19. Allen F, Locker D. A modified short version of the oral health impact profile for assessing health-related quality of life in edentulous adults. Int J Prosthodont 2002;15(5):446-450.

20. Galindo-Moreno P, León-Cano A, Ortega-Oller I, et al. Marginal bone loss as success criterion in implant dentistry: beyond $2 \mathrm{~mm}$. Clin Oral Implants Res 2015;26(4):e28-e34. DOI: 10.1111/clr.12324.

21. Ellis E, Macnamara JA. Components of adult class III malocclusion. J Oral Maxillofac Surg 1984;42(5):295-305. DOI: 10.1016/02782391(84)90109-5.

22. Weissheimer A, Menezes LM, Koerich L, et al. Fast three-dimensional superimposition of cone beam computed tomography for orthopaedics and orthognathic surgery evaluation. Int J Oral Maxillofac Surg 2015;44(9):1188-1196. DOI: 10.1016/j.ijom.2015. 04.001.

23. Devita R, Pinho S, Ustrell J, et al. Multidisciplinary oral rehabilitation in partially edentulous adult patients with malocclusion: a crosssectional survey study. J Clin Exp Dent 2018;10(12):1177-1183. DOI: 10.4317/jced.55282.

24. Al-Rethia R, Al-Dayel. A. A novel approach for a prosthetically driven treatment planning of a class III skeletal malocclusion: a case report. Saudi Dent J 2019;31:9-10. DOI: 10.1016/j.sdentj.2019.01.031.

25. Jain S, Aggarwal S, Mahajan T, et al. A transdisciplinary approach for treatment of class III malocclusion. 2019;8(10):3412-3415. DOI: 10.4103/jfmpc.jfmpc_601_19.

26. Peacock ZS, Lee $C C Y$, Klein $K P$, et al. Orthognathic surgery in patients over 40 years of age: indications and special 
considerations. 2014;72(10):1995-2004. DOI: 10.1016/j.joms.2014. 03.020 .

27. Dias L, Leandro W, Marcos R, et al. Combined orthognathic surgery and prosthetic treatment for class III skeletal malocclusion. Stomatos 2013;19(37):10-19.

28. Perillo L. Early treatment of dentoskeletal class III malocclusion: SEC III protocol. APOS Trends Orthod 2019;9:73-76. DOI: 10.25259/APOS56-2019.
29. Eslami S, Faber J, Fateh A, et al. Treatment decision in adult patients with class III malocclusion: surgery versus orthodontics. Prog Orthod 2018;19(1):28. DOI: 10.1186/s40510-018-0218-0.

30. Kim J-Y, Park JH, Jung H-D, et al. Factors affecting total treatment time in patients treated with orthognathic surgery using the surgeryfirst approach: multivariable analysis using 3D CT and scanned dental casts. J Clin Med 2020;9(3):641. DOI: https://doi.org/10.3390/ jcm9030641. 